University of Vermont

UVM ScholarWorks

College of Arts and Sciences Faculty

Publications

College of Arts and Sciences

5-1-2016

\title{
Species interactions and random dispersal rather than habitat filtering drive community assembly during early plant succession
}

Werner Ulrich

Uniwersytet Mikołaja Kopernika w Toruniu

Markus Klemens Zaplata

Brandenburgische Technische Universität Cottbus

Susanne Winter

Eberswalde University of Sustainable Development (HNE)

Wolfgang Schaaf

Brandenburgische Technische Universität Cottbus

Anton Fischer

Wissenschaftszentrum Weihenstephan für Ernährung, Landnutzung und Umwelt

See next page for additional authors

Follow this and additional works at: https://scholarworks.uvm.edu/casfac

Part of the Climate Commons

\section{Recommended Citation}

Ulrich W, Zaplata MK, Winter S, Schaaf W, Fischer A, Soliveres S, Gotelli NJ. Species interactions and random dispersal rather than habitat filtering drive community assembly during early plant succession. Oikos. 2016 May;125(5):698-707.

This Article is brought to you for free and open access by the College of Arts and Sciences at UVM ScholarWorks. It has been accepted for inclusion in College of Arts and Sciences Faculty Publications by an authorized administrator of UVM ScholarWorks. For more information, please contact scholarworks@uvm.edu. 


\section{Authors}

Werner Ulrich, Markus Klemens Zaplata, Susanne Winter, Wolfgang Schaaf, Anton Fischer, Santiago

Soliveres, and Nicholas J. Gotelli 


\title{
Species interactions and random dispersal rather than habitat filtering drive community assembly during early plant succession
}

\author{
Werner Ulrich, Markus Klemens Zaplata, Susanne Winter, Wolfgang Schaaf, \\ Anton Fischer, Santiago Soliveres and Nicholas J. Gotelli
}

\begin{abstract}
W. Ulrich (ulrichw@umk.pl), Chair of Ecology and Biogeography, Nicolaus Copernicus University in Torun, Lwowska 1, PL 87-100 Toruń, Poland. - M. K. Zaplata, Hydrology and Water Resources Management, Brandenburg Univ. of Technology Cottbus - Senftenberg, SiemensHalske-Ring 10, DE-03046 Cottbus, Germany. - S. Winter, Faculty of Forest and Environment, Section Applied Ecology and Zoology, Eberswalde Univ. of Sustainable Development, Alfred-Möller-Str. 5, DE-16225 Eberswalde, Germany. - W. Schaaf, Soil Protection and Recultivation, Brandenburg Univ. of Technology Cottbus - Senftenberg, Konrad-Wachsmann-Allee 6, DE-03046 Cottbus, Germany. - A. Fischer, Geobotany, Center of Life and Food Sciences, Technische Univ. München, Hans-Carl-von-Carlowitz-Platz 2, DE-85354 Freising, Germany. - S. Soliveres, Inst. of Plant Sciences, Univ. of Bern, Altenbergrain 21, CH-3013 Bern, Switzerland. - N. J. Gotelli, Dept of Biology, Univ. of Vermont, Burlington, VT 05405, USA.
\end{abstract}

\begin{abstract}
Theory on plant succession predicts a temporal increase in the complexity of spatial community structure and of competitive interactions: initially random occurrences of early colonising species shift towards spatially and competitively structured plant associations in later successional stages. Here we use long-term data on early plant succession in a German post mining area to disentangle the importance of random colonisation, habitat filtering, and competition on the temporal and spatial development of plant community structure. We used species co-occurrence analysis and a recently developed method for assessing competitive strength and hierarchies (transitive versus intransitive competitive orders) in multispecies communities. We found that species turnover decreased through time within interaction neighbourhoods, but increased through time outside interaction neighbourhoods. Successional change did not lead to modular community structure. After accounting for species richness effects, the strength of competitive interactions and the proportion of transitive competitive hierarchies increased through time. Although effects of habitat filtering were weak, random colonization and subsequent competitive interactions had strong effects on community structure. Because competitive strength and transitivity were poorly correlated with soil characteristics, there was little evidence for context dependent competitive strength associated with intransitive competitive hierarchies.
\end{abstract}

Temporal change in community structure is driven by three major processes: 1) filtering of species triggered by abiotic habitat and niche characteristics (Keddy 1992, Maire et al. 2012), 2) changes in the strength of positive and negative species interactions (Callaway and Walker 1997), and 3) differential colonisation (Butaye et al. 2001, Bochet et al. 2007). These processes comply with the familiar successional models of facilitation, tolerance, or inhibition (Connell and Slatyer 1977) as well as many other sequences (Grime 2001, Meiners et al. 2015). Many studies postulate a temporal increase in the frequency of competitive interactions and in the spatial complexity of community structure, from initially random occurrences of early colonisers towards spatially segregated and competitively structured associations in late successional stages (Baasch et al. 2009, del Moral 2009, Zaplata et al. 2013).

However, absence of species segregation does not necessarily imply a low impact of competition. The principle of competitive exclusion applied to a community predicts a fully transitive ordering of species abundances in which lower ranking species are always weaker competitors as compared to all higher ranking ones $(\mathrm{A}>\mathrm{B}>\mathrm{C}$ ). Consequently, it is tempting to assume that, among a set of similar sites communities of identical species composition will have identical competitive hierarchies, which should generate consistent rank abundance orderings of species.

However, this argument it too simplistic. Context dependent competitive strength (Chamberlain et al. 2014), priority effects and founder control (Palmer et al. 1997, Perry et al. 2003), and competitive loops (A $>$ B $>C>A$ ) can be important in multispecies communities (Gilpin 1975). Empirical studies have shown that competitive intransitivity can, in theory, allow weak competitors to coexist with strong ones (Huisman et al. 2001, Kerr et al. 2002, Laird and Schamp 2006, Reichenbach et al. 2007, Allesina and Levine 2011). Indeed, a recent field study that quantified pairwise competitive strength in plant communities reported intransitive competitive hierarchies among coexisting species (Soliveres et al. 2015). 
Most existing studies on either strongly hierarchical competitive networks or intransitive competition networks assume that competitive interactions are invariant across differing environmental conditions (but see Bowker et al. 2010, Soliveres et al. 2011, Ulrich et al. 2014a). Using a Markov chain model of invariant competitive strength, Ulrich et al. (2014b) showed that such invariant hierarchies, whether transitive or intransitive, predict similar abundance hierarchies among sites and do not generate species spatial segregation as predicted by competition-based assembly rules models (Diamond 1975). On the other hand, at a variety of spatial scales, replicated assemblages usually exhibit evidence for non-random species segregation, with some pairs of species co-occurring less often than expected by chance, even if they do not form perfect checkerboards (Ulrich and Gotelli 2010, 2013, Zaplata et al. 2013).

These conflicting results on species segregation can be reconciled if species competitive hierarchies vary in space or time. Context-dependent competitive strength (reviewed by Chamberlain et al. 2014), in which environmental conditions alter competitive hierarchies in space or time, generates variation in the dominance ordering of species, which can lead to spatial or temporal segregation of species pairs. Consequently, the degree of segregation should be positively correlated with the variability of these environmental factors. The strength of such correlations might therefore identify those factors that directly influence competitive strength.

In heterogeneous environments a variety of forces may override competitive effects, and generate patterns other than spatial segregation, even for small spatial scales at which species are able to interact directly (interaction neighbourhoods sensu Addicott et al. 1987). First, shared ecological requirements or mutualistic interactions might promote small-scale positive species associations (Horner-Devine et al. 2007) resulting in a modular spatial distribution of species. Second, if dispersal overrides competitive interactions, species richness is predicted to follow the gradient of local carrying capacity (habitat quality; Elton 1958, Mata et al. 2013) leading to a nested pattern of species occurrences in which the composition of species-poor patches is a proper subset of the composition of species-rich patches (Patterson and Atmar 1986, Ulrich et al. 2009). In theory, nestedness, modularity, and species segregation are therefore three different (although not mutually exclusive) patterns of community organisation (Leibold and Mikkelson 2002, Ulrich and Gotelli 2013). In practice, distinguishing statistically among these patterns is difficult (Ulrich and Gotelli 2013). Natural communities will often be intermediate between these extremes, depending on tradeoffs among species competition, dispersal, and habitat filtering (Leibold and Mikkelson 2002, Presley et al. 2010, Ulrich and Gotelli 2013).

Here we use a unique data set on early plant succession (Zaplata et al. 2010, 2013) to assess the change in plant community structure and patterns of species co-occurrences during the first seven years of community assembly. The study system and the specific sampling design allows for the first time a detailed analysis of the interplay between temporal community assembly, spatial patterns of co-occurrences, and changes in competitive strength. Previously we used these data to detect a temporal progression towards largescale negative spatial species associations (Zaplata et al.
2013) and towards increased utilization of plant trait space (Ulrich et al. 2014c). We further detected variability in phylogenetic community composition at small spatial scales that could be traced back to important soil attributes (Ulrich et al. 2014d).

Using co-occurrence and competitive strength analyses, we here link the strength of competitive interactions to the trends in community assembly at three spatial scales. We predict that 1) Segregation due to competitive interactions will be apparent only at small spatial scales. At large spatial scales, environmental variability should override the effect of direct competitive interactions. 2) As a consequence of 1), spatial and temporal species turnover should increase and the degree of nestedness should decrease with increasing spatial scale. 3) In the presence of small-scale habitat heterogeneity, the decrease in nestedness should be accompanied by an increase in modularity. 4) Along with the overall increase in species richness through the course of succession, the importance of competitive interactions, and the frequency of transitive competitive loops should increase in time.

\section{Material and methods}

\section{Study area and sampling}

From 2005 to 2011, we studied the early vegetation succession in a 6-ha constructed catchment Chicken Creek (German: Hühnerwasser), located in an open-cast lignite mine in northeastern Germany. Sand and loamy sand material originating from Pleistocene sediments was used for the construction of the 1-3.5 $\mathrm{m}$ top layer of the catchment to cover a 1-1.5 m clay layer (details in Gerwin et al. 2009). These substrates are characterized by a slightly alkaline $\mathrm{pH}(\sim 8)$ and low nutrient conditions that are typical during early primary succession. They are not contaminated by heavy metals or other environmentally hazardous substances. The particle size distribution of these substrates favours for the formation of soil crusts and the soil compacts during times of desiccation and soaks with water during times of heavy precipitation.

Immediately after construction of the top layer of the catchment was finished in October 2005, $11925-\mathrm{m}^{2}$ cells (Fig. 1A), and, in their corners, a total of 474 plots of $1-\mathrm{m}^{2}$ (Zaplata et al. 2010), were established (Fig. 1B). With this spatial arrangement, sets of four plots were formed with each plot having neighbours within the same cell at a distance of three meters (Fig. 1B). The distance between each adjacent set of plots was $15 \mathrm{~m}$. For the present study, we used 107 such sets. This number is not identical to the number of $25-\mathrm{m}^{2}$ cells because we removed incomplete sets and a few water-logged sets in the southern part of the catchment, which included a small area of surface water.

Vegetation was first recorded in 2005 in $3601-\mathrm{m}^{2}$ plots, and since 2006 annually in all plots and cells. For each species, we estimated the cover degree according to a modified Londo scale (Londo 1976; 0.1: $\leq 0.1 \%$; 0.5: $>0.1-$ $0.5 \% ; 1:>0.5-1 \% ; 2:>1-2 \%$, in $1 \%$ steps up to $10 ; 15$ : $>10-15 \%$, in $5 \%$ steps up to $30 ; 40:>30-40 \%$, in $10 \%$ steps up to 100). Bryophyta and Marchantiophyta were not identified to lower taxonomic levels. To study the influence 


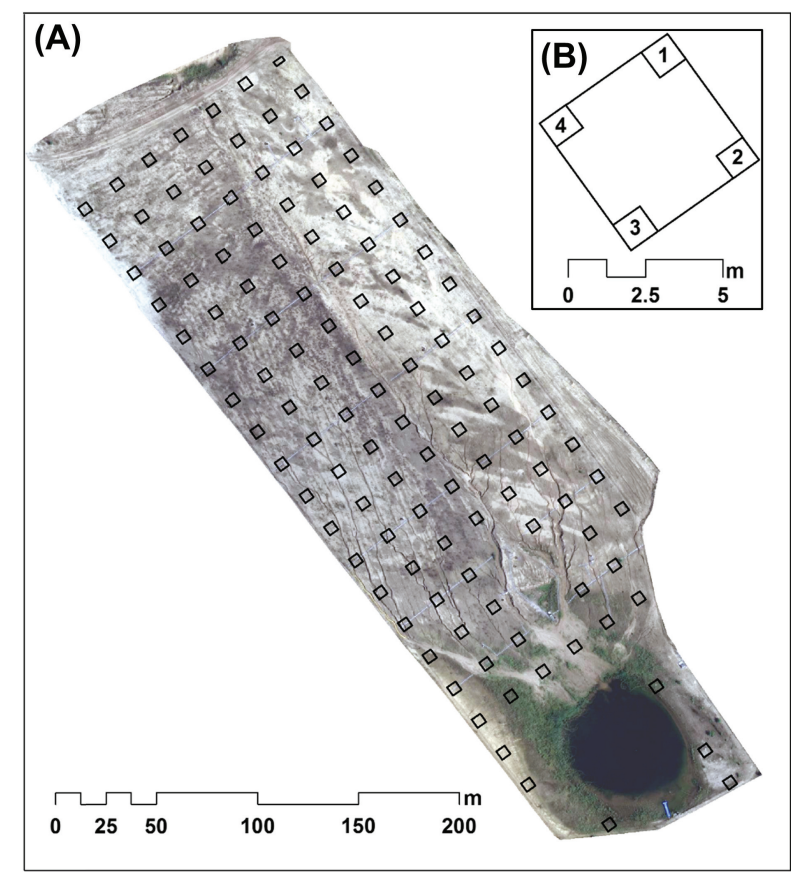

Figure 1. Chicken Creek catchment in August 2008 (aerial photograph provided by Vattenfall Europe Mining AG) showing the positions of the $25-\mathrm{m}^{2}$ cells (A). In the cell corners four $1 \mathrm{~m}^{2}$ plots form a set (B).

of initial substrate conditions on plant community assembly, we sampled the upper $30 \mathrm{~cm}$ of the substrate exactly at the grid immediately after completion of construction, before the vegetation became established. Soil properties such as $\mathrm{pH}$, texture, and carbonate content have previously been shown to be important drivers of plant community assembly in this study area (Zaplata et al. 2013, Ulrich et al. 2014c, d). Thus, we related these soil properties to our metrics of community structure. To assess the variability in species richness among plots and sets, we used the index of Lloyd $\left(J=\frac{s^{2}}{\bar{x}^{2}}-\frac{1}{\bar{x}}+1\right.$, where $s$ denotes the standard deviation and $\bar{x}$ the mean number of species; Lloyd 1967). Values of Lloyd's index less than 1.0 indicate species richness distributions more equal (overdispersed), and values greater than 1.0 more clumped (underdispersed), than expected from a Poisson random process. The raw data used for all analyses is available in the Supplementary material Appendix 1.

\section{Metrics of community structure}

For all $25-\mathrm{m}^{2}$ cells, sets $\left(4-\mathrm{m}^{2}\right)$, and plots $\left(1-\mathrm{m}^{2}\right)$, we constructed species abundances matrices (species in rows, samples in columns) for each study year. Thus, the single matrix for the $25-\mathrm{m}^{2}$ cells contained 119 columns, the matrices for the sets $\left(4-\mathrm{m}^{2}\right) 107$ columns, and the matrices for the plots $\left(1-\mathrm{m}^{2}\right)$ between 360 and 426 columns. The set scale provided therefore information on small scale spatial variability in plant community structure, whereas the plots and cells captured different levels of resolution at the catchment scale. For each matrix, we estimated the degree of species segregation (negative species associations) using the abundance-weighted C-score (WCS; abbreviated $\mathrm{CA}_{\text {st }}$ in Ulrich and Gotelli 2010). The WCS is a normalized count of the number of abundance checkerboard submatrices $(\{\{a, b\},\{c, d\}\}$ in which $a$ to $d$ represent species relative abundances and either $a>c$ and $d>b$ or $a<c$ and $d<b$. A high WCS score is therefore an indication of negative species association.

Nestedness refers to the ordered loss of species along a focal environmental or ecological gradient (Patterson and Atmar 1986, Ulrich et al. 2009) and is therefore opposite (although not mutually exclusive) to species turnover (Ulrich and Gotelli 2013). Below we quantified the degree of nestedness using the standard NODF (nestedness from overlap and decreasing fill) metric, which is a normalised count of the degree of species overlap among the sequence of plots ordered according to decreasing species richness (Almeida-Neto et al. 2008). NODF ranges from zero (perfect species turnover) to 1 (perfect nestedness).

'Seriation' sorts rows and columns of a matrix in a way that maximizes the number of presences along the matrix diagonal (Leibold and Mikkelson 2002). This diagonal is equivalent to the first axis of a correspondence analysis. Ulrich and Gotelli (2013) and Ulrich et al. (2014a) showed that the rank correlation of row and column positions of all non-empty cells in the 'seriated' matrix is then a measure of directional species segregation (species turnover). Following Ulrich and Gotelli (2013), we used the respective coefficient of determination $\mathrm{R}^{2}$ as the test statistic for species turnover across our study plots.

Metrics of species co-occurrences like $\mathrm{R}^{2}$, NODF, and WCS are constrained by matrix geometry (Gotelli and Ulrich 2012) and cannot be compared directly. Therefore, we used a null model approach (Gotelli and Ulrich 2012) and estimated the effect sizes for each of these metrics as the difference between the observed metric and the expected value. The expected values were calculated by using a null model that randomises the focal matrix by assigning individuals to the plots with probabilities of assignment of different species proportional to overall species abundances, Random placement of individuals in a simulation was terminated when the total number of individuals of each species in the observed data was reached. Ulrich and Gotelli (2010) advocated this null model (termed IT) for abundance data because it best accounted for the effects of a priori unequal occurrences probabilities (the mass effect).

We used the approach of Ulrich et al. (2014b) to infer pairwise competitive interactions of species. If we assume that abundances are determined primarily by competitive interactions, any matrix containing the pairwise transition probabilities of the outcome of a species interaction (the probability that species $i$ replaces species $j$ ) be can be unequivocally translated into a vector of predicted relative abundances. However, going the opposite direction - inferring competitive strength from relative abundances - is not straightforward. Nevertheless, Ulrich et al. (2014b) successfully implemented a 'reverse engineering' approach: a large pool of randomly constructed candidate matrices of competitive strengths can be sorted to find the matrix that best predicts the observed abundance distribution.

Following Ulrich et al. (2014b), we calculated, for each plot, set and cell, 100000 random species $\times$ species 
competitive strengths matrices, translated these into column-stochastic transition matrices, and used a Markov chain model to predict species abundances for each matrix (see Ulrich et al. 2014b and Soliveres et al. 2015 for computational details). For each plot, set, and cell, we compared the predicted and observed species abundances by rank order correlation $\left(r_{C}\right)$ and chose the best-fitting competition matrix to assess the maximum impact of competitive interactions on community assembly (Soliveres et al. 2015).

High values of $r_{C}$ point indicate a good match of the competitive strength matrix with the observed matrix of species abundances, and therefore are consistent with a scenario in which species interactions are an important driver of species abundance distributions. In contrast, low $\mathrm{r}_{\mathrm{C}}$ values imply a minor contribution of species interactions to community assembly (Ulrich et al. 2014b). Importantly, because the predicted abundance distributions are derived from the observed data, high $r_{C}$ scores do not exclude the possibility that other factors than competition influence observed abundances. However, low $r_{C}$ scores imply that no pairwise interaction matrix model is able to successfully predict observed abundances, suggesting that species interactions are relatively unimportant.

We also calculated the metric

$\tau_{\mathrm{C}}=\frac{2 \mathrm{~N}\left(c_{i j}<c_{j i}\right)}{\mathrm{m}(\mathrm{m}-1)}(i<j)$

in which the entries $c_{i j}$ are from the competition matrix $\left(c_{i j}=\left(1-c_{j i}\right)\right)$ and denote the probability that species $i$ replaces species $j$ in a competitive interaction. $\tau_{C}$ quantifies the proportion of transitive pairwise interactions in the competition matrix (i.e. competitive strengths; Ulrich et al. $2014 \mathrm{~b}$ ). The higher $\tau_{\mathrm{C}}$ is, the more hierarchical (i.e. transitive) is the competition network. Ulrich et al. (2014b) found values of $\tau_{\mathrm{C}}>0.95$ to indicate a fully transitive competitive hierarchy. In contrast, a low $\tau_{\mathrm{C}}$ indicates intransitive competitive interactions with little effect on total species richness.

\section{Linking metrics of turnover, dominance, and competitive strength}

We used general linear modelling (GLM, orthogonal sums of squares) at the set $\left(4-\mathrm{m}^{2}\right)$ and cell $\left(25-\mathrm{m}^{2}\right)$ levels to explore the effects of small-scale habitat heterogeneity and competitive strength on patterns of species co-occurrence. To account for the spatial non-independence of the plots, we used spatial eigenvector mapping (Hawkins 2012) and included the dominant eigenvector EV1 of the Euclidean distance matrix as an additional predictor variable in the models. This eigenvector explained $83 \%$ of variance in spatial structure. Multicollinearity among the variables was always low.

During subsequent study years, samples were taken on the same plots, as is required for any real-time series. Consequently, temporal autocorrelation might influence our results by artificially inflating the degrees of freedom. As soil conditions were also and inevitably autocorrelated in time, we hesitated to use a simple nested GLM design. Nevertheless, to account for this type of temporal pseudo-replication we followed a similar approach to Ulrich et al. (2014c) and restricted the degrees of freedom in the parametric t-tests for all single predictors to the total number of $1-\mathrm{m}^{2}$ plots
(426 instead of $>1280$ ) to minimize the inflation of the temporal degrees of freedom and the possible bias when estimating p-values.

Next, we related our metrics of competitive strength to patterns of species spatial co-occurrences using the regression model

$\mathrm{Y}=\mathrm{a}_{0}+\mathrm{a}_{1}$ species $+\mathrm{a}_{2}$ carbonate $+\mathrm{a}_{3} \mathrm{pH}+\mathrm{a}_{4}$ sand + $\mathrm{a}_{5} \mathrm{EV} 1+\mathrm{a}_{6}\left(\tau_{\mathrm{C}}\right)$

in which the dependent variable $\mathrm{Y}$ was the effect size of WCS, NODF or $\mathrm{R}^{2}$. We applied this regression model to each study year to get information on how the relationship between $\tau_{\mathrm{C}}$ and $\mathrm{Y}$ changed during succession while accounting for species richness and substrate characteristics. Finally, we used Mantel correlations applied to the set level to assess whether spatial variability in competitive strength $\left(\mathrm{r}_{\mathrm{C}}, \tau_{\mathrm{C}}\right)$ and co-occurrence (WCS, NODF, R ${ }^{2}$ ) metrics was dependent on the spatial distances and the variability in substrate variables (carbonate, $\mathrm{pH}$, sand). General and generalised linear models were calculated using Statistica (Statsoft), whereas co-occurrence analyses were performed with the Turnover and NODF software applications, freely available at $<$ www.ulrichw.umk.pl $>$.

\section{Results}

\section{Trends in community structure}

Total species richness increased from 16 species initially in 2005 to 141 species in 2011, with an average richness per $\mathrm{m}^{2}$ of $0.05 \pm 0.35$ species in 2005 to $14.8 \pm 4.4$ (mean $\pm \mathrm{SD}$ ) in 2011. Variability in species richness among the $1-\mathrm{m}^{2}$ plots, 4- $\mathrm{m}^{2}$ sets, and $25-\mathrm{m}^{2}$ cells were in all years not significantly different from a Poisson random expectation (all bootstrapped Lloyd index values were not significantly different from 1.0 at $\mathrm{p}<0.05)$.

The increase in species richness through time was accompanied by a constant change in the pattern of species co-occurrences (Fig. 2). Across time, species spatial turnover decreased (Fig. 2A) within the sets, but increased among them (Fig. 2B). Since 2008, turnover at the set level was, on average, less than expected from the null assumption (bootstrapped t-tests: $\mathrm{p}<0.001$, Fig. 2A). Turnover was always lower than expected by the null model when calculated among the sets (Fig. 2B). This comparably low turnover was accompanied by increasing nestedness within and between the sets (positive effect sizes, Fig. 3C-D), although there was no significant temporal trend in NODF. The WCS metric that quantifies spatial segregation with respect to species abundances did not change significantly through time at the set level (Fig. 2E) but increased above this level (Fig. 2F). Within the sets, variability of all three metrics decreased in time (Fig. 2A, C, E).

The GLM approach confirmed these spatial and temporal trends in the patterns of species co-occurrences (Table 1): time accounted for $22.8 \%$ to $46.4 \%$ and spatial scale for 0.1 to $18.7 \%$ of variance in species co-occurrences. The significant year $X$ scale interaction terms for $\mathrm{R}^{2}$ and NODF indicate that temporal patterns in species co-occurrences were 


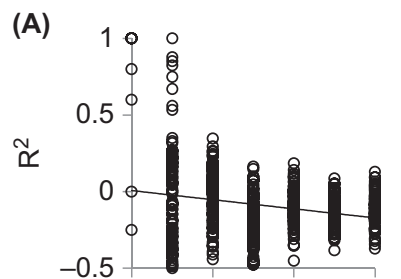

(C)
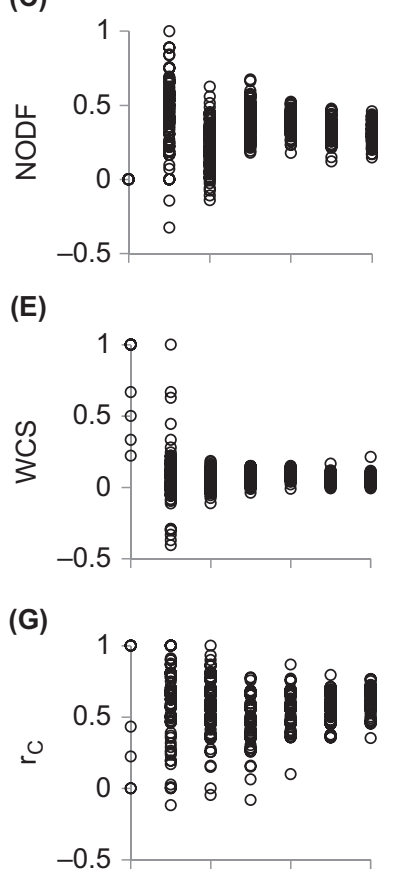

(l)

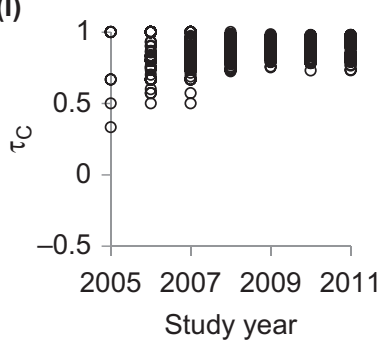

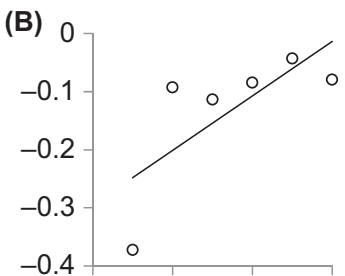

(D)

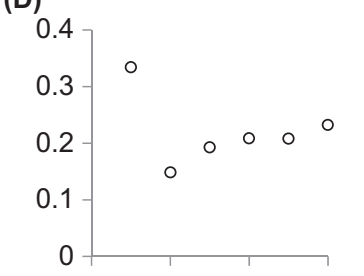

(F)

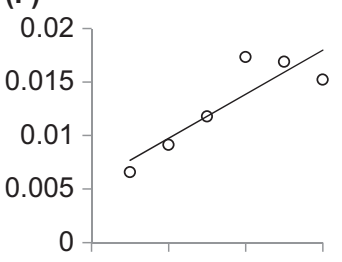

(H)

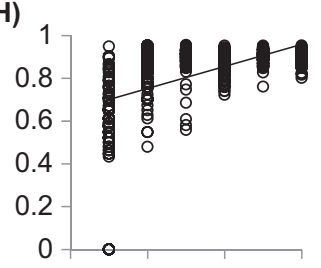

(J)

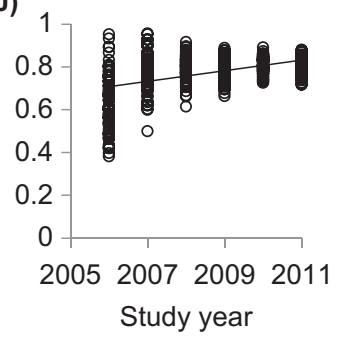

Figure 2. Temporal trends of effect sizes of species turnover $\left(\mathrm{R}^{2}\right)(\mathrm{A}$, B), NODF, (C, D), and WCS (E, F) among the 4- $\mathrm{m}^{2}$ set (A, C, E) and among the $25-\mathrm{m}^{2}$ cell $(\mathrm{B}, \mathrm{D}, \mathrm{F})$ resolution scale. Respective trends of competitive strength $\left(\mathrm{r}_{\mathrm{C}}\right)(\mathrm{G}, \mathrm{H})$ and degrees of transitivity $\left(\tau_{\mathrm{C}}\right)(\mathrm{I}, \mathrm{J})$ at the $4-\mathrm{m}^{2}(\mathrm{G}, \mathrm{I})$, and $25-\mathrm{m}^{2}(\mathrm{H}, \mathrm{J})$ resolution. The trends for $r_{C}$ and $\tau_{C}$ at the $1-\mathrm{m}^{2}$ resolution were very similar to those at the 4- $\mathrm{m}^{2}$ scale and therefore not shown. Regression lines are significant at $\mathrm{p}<0.001(\mathrm{~A}, \mathrm{H}, \mathrm{J})$ and $\mathrm{p}<0.05(\mathrm{~B}, \mathrm{~F})$.

spatial- and temporal-scale specific. Post hoc comparisons identified particularly strong differences in $\mathrm{R}^{2}$ and NODF between the sets for the years 2007 and 2008 (Tukey tests: $\mathrm{p}<0.001)$. The three metrics were not significantly influenced by species richness and substrate attributes (Table 1).

\section{Scale matters when looking at competition and community structure during succession}

The $r_{C}$ metric decreased with increasing species richness and was independent of substrate attributes (Table 2). Age

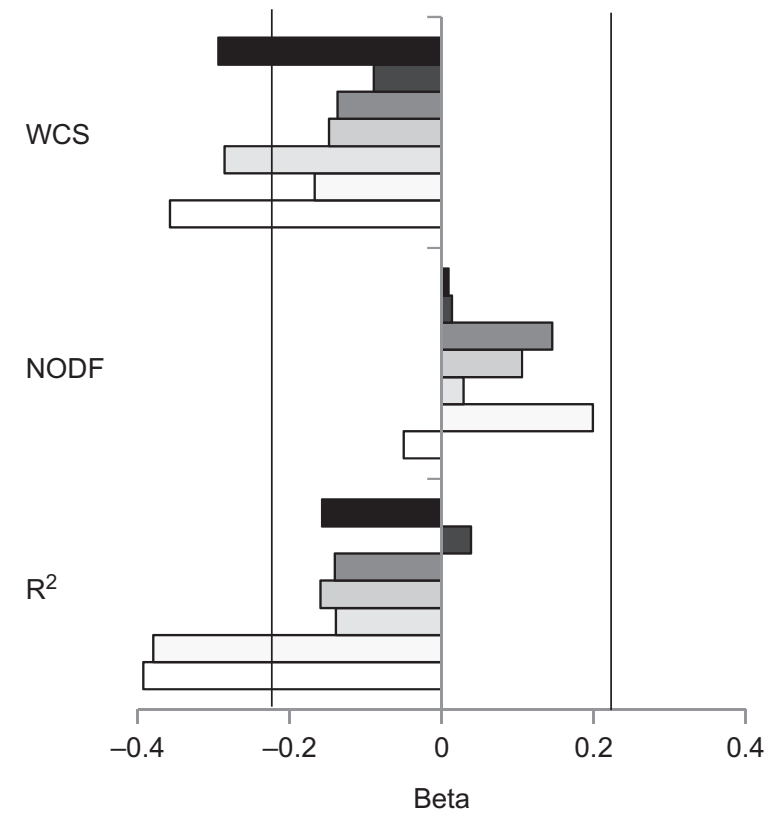

Figure 3. Annual GLM models applied to the set level $\tau_{\mathrm{C}}$ as dependent variables. Given are the beta values for $X$ of the model $Y=a_{0}$ $+\mathrm{a}_{1}$ species $+\mathrm{a}_{2}$ carbonate $+\mathrm{a}_{3} \mathrm{pH}+\mathrm{a}_{4}$ sand $+\mathrm{a}_{5} \mathrm{EV} 1+\mathrm{a}_{6}\left(\tau_{\mathrm{C}}\right)$, with $\mathrm{Y}$ being effects sizes of WCS, NODF, and $\mathrm{R}^{2}$. The vertical lines denote the approximate parametric $1 \%$ significance levels. Bar shadows run from white (year 2005) to black (year 2011).

and spatial scale together explained as much as $64 \%$ of the variance in $\mathrm{r}_{\mathrm{C}}$. At the set level, the possible strength of interspecific competition was $r_{C}=0.56 \pm 0.16$ (mean \pm standard deviation) and did not increase during succession (Fig. $2 \mathrm{G}$ ). At the $25-\mathrm{m}^{2}$ cell resolution, $\mathrm{r}_{\mathrm{C}}$ significantly increased during succession (mean $r_{C}=0.83 \pm 0.17$; Fig. $2 \mathrm{H}$ ).

The proportion of transitive competitive hierarchies increased during succession (Fig. 2I, J) although this was statistically not significant at the $1-\mathrm{m}^{2}$ plot and $25-\mathrm{m}^{2}$ cell levels (Fig. 2I: both $\mathrm{p}>0.05$ ). Full transitivity was most frequent at the set level (24.9\% of communities, Fig. 2I) and decreased at the smaller spatial scale of the plot $(10.0 \%)$ and the larger cell scale (0.5\%; Fig. 2J). Transitivity was weakly although significantly negatively correlated with species richness at the plot level (Table 2). This negative correlation was visible in all study years and was strongest in 2005 (Pearson $\mathrm{r}=-0.80, \mathrm{p}<0.01)$ and $2006(\mathrm{r}=-0.51, \mathrm{p}<0.001)$. In later years, however, it became increasingly weak and statistically non-significant (all $\mathrm{r}<|-0.14|, \mathrm{p}>0.1$ ).

After statistically controlling for possible influences of species richness, spatial autocorrelation, and substrate characteristics, NODF and WCS, and to a lesser degree $\mathrm{R}^{2}$, were strongly linked to $\tau_{C}$ (Table 2, Fig. 3). The degree of competitive transitivity $\tau_{C}$ was negatively correlated with spatial abundance segregation and species turnover, but positively correlated with NODF (Fig. 3).

\section{The spatial dimension of community structure during succession}

Effect sizes of NODF and $\mathrm{R}^{2}$ with respect to the proportional null model were significantly spatially autocorrelated 
Table 1. General linear modelling of effect sizes of species spatial co-occurrence in dependence on species richness and soil parameters as quantitative, and age since catchment construction and spatial scale as qualitative predictors. Given are regression beta scores and variance partitioned coefficients of determination $r^{2}$ (variable). $r^{2}$ (model) refers to the whole regression model. ${ }^{*}: p<0.05, * *: p<0.01$, $* * *: p<0.001$.

\begin{tabular}{|c|c|c|c|c|c|c|c|}
\hline \multirow[b]{2}{*}{ Variable } & \multirow[b]{2}{*}{ DF } & \multicolumn{2}{|c|}{$\mathrm{R}^{2}$} & \multicolumn{2}{|c|}{ NODF } & \multicolumn{2}{|c|}{ WCS } \\
\hline & & beta & $\mathrm{r}^{2}$ (variable) & beta & $r^{2}$ (variable) & beta & $r^{2}($ variable $)$ \\
\hline EV1 & 1 & -0.078 & $0.011^{*}$ & 0.032 & $0.007^{*}$ & -0.022 & 0.001 \\
\hline Species & 1 & -0.047 & $<0.001$ & 0.067 & 0.001 & 0.044 & $<0.001$ \\
\hline Carbonate & 1 & -0.118 & $0.008^{*}$ & 0.05 & $0.006^{*}$ & -0.073 & 0.004 \\
\hline Sand & 1 & -0.328 & 0.001 & 0.135 & $<0.001$ & -0.008 & $<0.001$ \\
\hline $\mathrm{pH}$ & 1 & 0.059 & $<0.001$ & -0.046 & $<0.001$ & -0.308 & 0.001 \\
\hline$r_{C}$ & 1 & -0.067 & $<0.001$ & 0.471 & $0.057^{* * *}$ & -0.424 & $0.017^{* *}$ \\
\hline Age & 6 & & $0.228^{* * *}$ & & $0.241 * * *$ & & $0.464 * * *$ \\
\hline Scale & 1 & & 0.001 & & $0.187^{* * *}$ & & $0.044 * * *$ \\
\hline Age $\times$ Scale & 5 & & $0.160^{* * *}$ & & $0.066^{* * *}$ & & 0.014 \\
\hline Error & 426 & & & & & & \\
\hline $\mathrm{r}^{2}($ model $)$ & & & $0.566^{* * *}$ & & $0.566^{* * *}$ & & $0.545^{* * *}$ \\
\hline
\end{tabular}

(Table 1). Mantel tests (Fig. 4A) confirmed these results and returned for the majority of study years positive - although weak $(<2 \%$ of variance explained $)-$ spatial correlations. In contrast, abundance based patterns of co-occurrences measured by WCS were not clearly spatially autocorrelated (Fig. 4A). There was also a general trend towards positive correlations between differences in substrate characteristics and the respective differences in species co-occurrences $\left(\mathrm{R}^{2}\right.$, NODF; Fig. 4B). These results suggest that variability in substrate characteristics (Fig. 4B), rather than the average values (Table 1), have most influence on patterns of species co-occurrences. These trends were strongest for the first study year. The competitive strength metrics were not spatially autocorrelated (Table 2, Fig. 4A) but were in all study years weakly positively correlated with substrate conditions (Fig. 4B).

\section{Discussion}

\section{Temporal trends in community assembly}

Some theories of plant succession predict species richness to increase until a mid-successional maximum is reached (Horn 1974). In our study system, such a maximum was not visible after seven years of succession (Ulrich et al. 2014c, d). In line with major hypotheses on primary succession, we also predicted 1) an initial random pattern of species cooccurrences as a consequence of spatially random external colonisation and germination from the soil seed bank (Hubbell 2001, Baasch et al. 2009, del Moral 2009). This was not the case in our study system. The initial spatial distribution of species was significantly segregated at the set level (Fig. 3A, D, t-test: $\mathrm{p}<0.01$ ) and aggregated at the cell level (Fig. 3B, E; bootstrapped t-test: $\mathrm{p}<0.01$ ). Within the Connell-Slatyer (1977) succession framework, the inhibition model is consistent with a pattern of initial segregation by pioneer species at a small spatial scale. In our study, one of the earliest dominant plant species, Conyza canadensis, is allelopathic (Djurdjević et al. 2011) and can suppress the establishment of other early colonists. Allelopathy by pioneer species is also not in accordance with neutral models that assume random dispersal of ecologically equivalent species (Hubbell 2001, Alonso et al. 2006). Rather, our results suggest that preferential "safe sites" (sensu Harper 1977) are shared by many colonizing species, but that species interactions reduce the establishment success of these early colonists.

Surprisingly and again contrary to our first prediction, the initial species segregation at the set level was followed by a trend towards random co-occurrences in comparison to the null model (Fig. 2). Apparently, the arrival of new species mediated the initial spatial pattern, resulting in a random distribution of species. Only at the largest, whole-catchment scale did co-occurrences became increasingly segregated (Fig. 3 and Zaplata et al. 2013) through time, and this segregation was associated with the underlying large-scale variation in substrate conditions (Ulrich et al. 2014c). Consequently our results demonstrate a temporal divergence in plant community structure at the catchment scale. Further, our study demonstrates that not only spatial but also temporal patterns of species co-occurrences differ across spatial scales.

Table 2. General linear modelling of metrics of competitive strength $\left(\mathrm{r}_{\mathrm{C}}\right)$ and transitivity $\left(\tau_{\mathrm{C}}\right)$ in dependence on species richness and substrate parameters as quantitative, and age since catchment construction and spatial scale as qualitative predictors. Given are regression beta scores and variance partitioned coefficients of determination $r^{2}$ (variable). $r^{2}$ (model) refers to the whole regression model. In the case of the qualitative predictors ' $<0^{\prime}$ and ' $0>^{\prime}$ signs indicate the respective covariance. ${ }^{*}: p<0.05, * *: p<0.01, * * *: p<0.001$.

\begin{tabular}{lrrcrlcc}
\hline & & \multicolumn{3}{c}{$\mathrm{r}_{\mathrm{C}}$} & & \multicolumn{2}{c}{$\tau_{\mathrm{C}}$} \\
\cline { 7 - 8 } \cline { 6 - 7 } Variable & DF & beta & $\mathrm{r}^{2}$ (variable) & & beta & $\mathrm{r}^{2}$ (variable) \\
\hline EV1 & 1 & 0.005 & 0.001 & & -0.003 & 0.001 \\
Species & 1 & -0.066 & $0.009^{*}$ & & -0.04 & $0.006^{*}$ \\
Carbonate & 1 & -0.008 & 0.001 & & -0.002 & $<0.001$ \\
Sand & 1 & 0.047 & $<0.001$ & & -0.013 & $<0.001$ \\
$\mathrm{pH}$ & 1 & 0.04 & $<0.001$ & & -0.026 & $<0.001$ \\
$\mathrm{r}_{\mathrm{C}}$ & 1 & - & - & & 0.404 & $0.141^{* * *}$ \\
Age & 6 & $>0$ & $0.074^{* * *}$ & $>0$ & $0.019^{* *}$ \\
Scale & 2 & $<0$ & $0.322^{* * *}$ & $<0$ & $0.184^{* * *}$ \\
Age $\times$ Scale & 10 & & $0.118^{* * *}$ & & 0.006 \\
Error & 426 & & & & \\
$\mathrm{r}^{2}$ (model) & & & $0.66^{* * *}$ & & $0.489^{* * *}$ \\
\hline
\end{tabular}



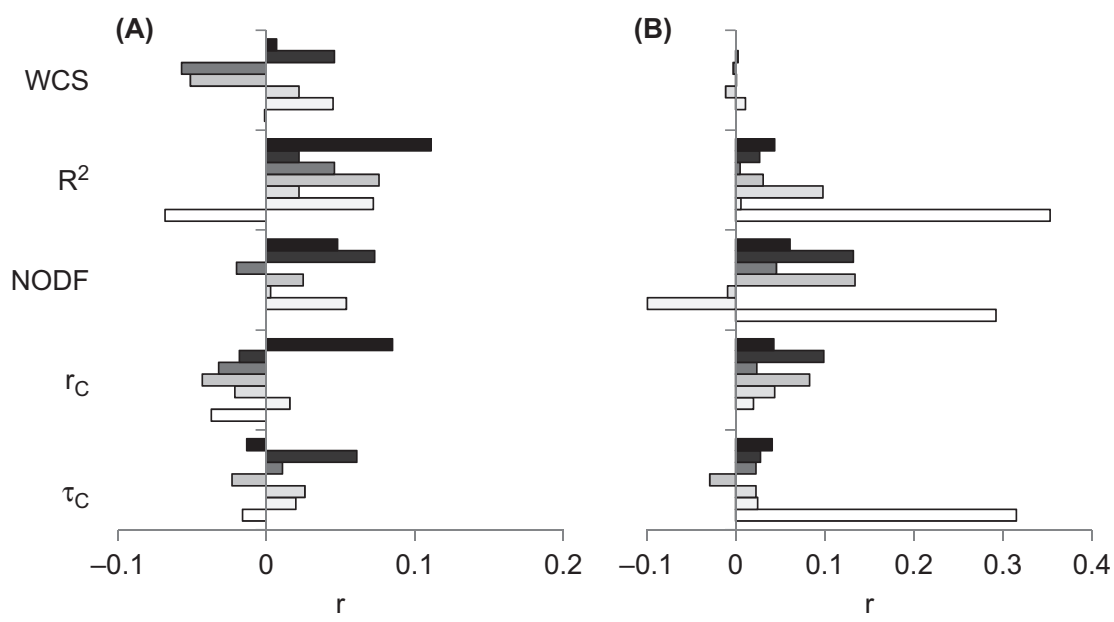

Figure 4. Mantel correlations $r$ of metrics on community structure (effects sizes of WCS, NODF and $\left.\mathrm{R}^{2}\right)$ and competitive strength $\left(\mathrm{r}_{\mathrm{C}}, \tau_{\mathrm{C}}\right.$ ), and Euclidean spatial (A) and soil characteristics (B) distances. Data from the set level. Bar shadows run from white (year 2005) to black (year 2011). Except for $2005(n=81)$ the large numbers of set pairs $(n>1000)$ caused correlation coefficients $r>|0.03|$ to be significant at $\mathrm{p}<0.01$. For 2005 correlations $\mathrm{r}>|0.29|$ are significant at $\mathrm{p}<0.01$.

\section{Spatial patterning of community assembly}

A first major aim of our study was to infer the spatial trends in patterns of species co-occurrences during early plant succession. Previous work on small-scale variability focused on environmental stress and found similar positive correlations of species aggregation and nutrient availability and increases in species segregation with decreasing substrate $\mathrm{pH}$ (Maestre et al. 2009). Kikvidze et al. (2005) and Dullinger et al. (2007) reported positive relationships between species aggregation and plant cover and biomass, respectively. Our findings only partly corroborate these results and do not match well with our first two predictions on the scale dependence of species spatial segregation (Table 1, Fig. 3, 5). Although NODF and $R^{2}$ - but not the abundance based WCS metric - were spatially autocorrelated and related to substrate properties (Fig. 4), these effects explained in nearly all cases less than $1 \%$ of variance. Of the substrate variables, only carbonate content was weakly positively linked to the degree of spatial aggregation (Fig. 4B). Although this finding is in line with filtering effects at the habitat patch scale (as reviewed by Götzenberger et al. 2011), we notice that the observed effects in these previous studies and in our study system were usually small (Table 1, Fig. 4). Moreover, substrate conditions were not clearly linked to differences in species relative abundances (Table 1, Fig. 1). These findings indicate, that small-scale variability in substrate conditions (Zaplata et al. 2013) might not be the strongest driver of community assembly, although soil may be very important at larger spatial scales (Tuomisto et al. 2014, Zuquim et al. 2014). Our findings are thus in line with a hierarchical concept of succession (Pickett et al. 1987), which emphasizes site availability, and differences in species colonization and performance as being more important.

In a previous study (Ulrich et al. 2014c) we reported that small-scale variability in phylogenetic community composition was correlated with substrate characteristics. Because differences in phylogenetic community structure might be linked to species composition (Webb et al. 2002), we expected to see a correlation between substrate characteristics and species co-occurrences (Bennett et al. 2013). In this study, small-scale substrate variability was not closely related to species composition. Habitat filtering implies small-scale aggregation of species co-occurrences and a significant degree of species turnover at larger spatial scales (Presley et al. 2010). This is equivalent to a modular meta-community organisation (Presley et al. 2010, Borthagary et al. 2014). Species cooccurrences were indeed scale dependent (Fig. 2). Significant nestedness was accompanied by a lack of species segregation at the set scale (Fig. 2). However, this finding and the low degree of species turnover at the $4-\mathrm{m}^{2}$ set and $25-\mathrm{m}^{2}$ cell scales do not match a pattern of modular meta-community organisation, and suggests that the measured substrate variables do not act as strong environmental filters.

We also did not find support for our third prediction of decreasing nestedness and increasing modularity driven by substrate characteristics. Instead, the Poisson random variability in species richness observed at all spatial-scales suggests that random species colonisation was more important than habitat filtering. One possible explanation for this pattern invokes the temporal increase in soil heterogeneity due to ecological engineering by plants (Cuddington and Hastings 2004). This would reduce the impact of filtering on species composition leading to medium scale randomisation of species composition in time and to an increased importance of competition at the plot level.

Our first two predictions were partly based on the framework of nested, modular, and turnover patterns advocated by Leibold and Mikkelson (2002) and Presley et al. (2010) who linked these respective patterns to contrasting processes of community assembly. Our results provide weak support for this classification. Effect sizes of $\mathrm{R}^{2}$ (turnover) and NODF (nestedness) were only moderately negatively correlated at the set levels $(r=-0.53$, Fig. 2) and even correlated positively at the cell level ( $\mathrm{r}=0.18$, Fig. 2). Consequently, many set and cells could not be clearly separated along the nestedness - turnover continuum. Our results contrast with a recent study by Meynard et al. (2013), who used snap-shot 
(i.e. non-dynamic) data at several spatial scales and argued for clear indication of modularity.

However, our results also point to a shortcoming of the triangle model proposed by Leibold and Mikkelson (2002). Although modularity is unequivocally defined as 'link-dense regions in ecological networks' (Olesen et al. 2007) there is no rigorous way to measure modularity (Newman 2006) and therefore this pattern may not be easy to discern with classic frequentist $(\mathrm{p}<0.05)$ yes/no tests for modularity (Gotelli and Ulrich 2012).

Our study design did not allow us to definitively disentangle dispersal and seed bank effects on the initial community composition and competitive relationships. Given the strong evidence for distance-dependent colonisation from neighbouring sites during primary succession (Dzwonko 1993, Bochet et al. 2007, Latzel et al. 2011), we speculate that the non-random occurrences of plant seeds in the catchment substrate had a major effect on the earliest community composition. However, additional study is needed to assess seed bank contributions, and potential tradeoffs between dispersal and competition during early plant succession.

\section{The interplay of competition and species co-occurrence}

Major models of community assembly focus on competitive exclusion (Diamond 1975, Chesson 2000). Ideally, therefore, co-occurrence analysis should be combined with the analysis of competitive hierarchies (Soliveres et al. 2015). A new framework developed by Ulrich et al. (2014b) allows for the first time such a conjoint analysis. This framework predicts an increasing frequency of negative interactions and transitive hierarchies through the course of succession. Our results are in line with these predictions and with our fourth starting hypothesis that importance of competitive interactions, and the frequency of transitive competitive hierarchies should increase in time (Fig. 2). They point to a clear increase in the importance of competitive interactions during early succession but a weaker effect of competition at larger spatial scales (Table 2). The latter observation is most parsimoniously explained by the fact that competition acts at the scale of individual interactions between plants and thus should be strongest at the smallest spatial resolution (i.e. the interaction neighbourhood scale). This interpretation is also in line with our finding that the variability in competitive strength and in metrics of co-occurrences were strongest in the initial phases of succession and decreased through time (Fig. 2). Probably the interplay of competition, facilitation and filtering causes communities at small scales to become more similar in time and hence converge. These processes do not exclude divergence in community composition among these small scale communities as indicated by the pronounced increase in spatial segregation and competitive strength among the cells (Fig. 2).

Our approach has allowed us to directly link competitive strength and patterns of co-occurrences (Table 2, Fig. 3). Community assembly theory (Diamond 1975, Weiher and Keddy 1999) and competitive intransitivity models (Laird and Schamp 2006, Ulrich et al. 2014b) predict contrasting patterns, and we were able to evaluate these predictions at different temporal and spatial scales. The competitive intransitivity models of Allesina and Levine (2011) and Ulrich et al. (2014b) assume constant pair-wise competitive interactions. Stable abundance hierarchies (Ulrich et al. 2014b) and coexistence is then promoted by the internal dynamics of the competitive looping that works according to rock-paper-scissors games (Allesina and Levine 2011, RojasEchenique and Allesina 2011, Allesina and Tang 2012). This interpretation is corroborated by our finding (Fig. 3) that high degrees of abundance segregation and species turnover were in all study years linked to competitive loops (low transitivity). If additionally interaction strength is contextdependent and changes with environmental conditions (Grime 1973, Chamberlain et al. 2014, Gioria and Osborne 2014), abundance hierarchies are predicted to differ from site to site leading to segregated patterns of abundances and species co-occurrences. This effect is expected to increase with spatial scale (Fig. 2) and thus the model predicts a positive correlation of the degree of species segregation with spatial and/or environmental distance. Our finding of the spatial autocorrelation of $\mathrm{R}^{2}$ (Fig. 4) corroborates this interpretation.

Acknowledgements - Author contributions: WU, NG and SS provided theoretical background, AF and SW developed the field design, MKZ, SW and AF collected the floristic data and created the database, and WS collected and analysed the substrate samples. WU performed the competition and co-occurrence analysis. WU wrote the first draft of the manuscript, and all authors contributed substantially to revisions. This study was part of the Transregional Collaborative Research Centre 38 (SFB/TR 38: ecosystem assembly and succession), which was financially supported by the Deutsche Forschungsgemeinschaft (DFG, Bonn) and the Brandenburg Ministry of Science, Research and Culture (MWFK, Potsdam). The authors thank the working group Z1 (monitoring) members of the SFB/TRR 38, who helped us to perform this study and the Vattenfall Europe Mining AG for providing the research site and graphical material. WU acknowledges funding from the Polish National Science Centre (2014/13/B/NZ8/04681).

\section{References}

Addicott, J. F. et al. 1987. Ecological neighborhoods: scaling environmental patterns. - Oikos 49: 340-346.

Almeida-Neto, M. et al. 2008. A consistent metric for nestedness analysis in ecological systems: reconciling concept and quantification. - Oikos: 117: 1227-1239.

Allesina, S. and Levine, J. M. 2011. A competitive network theory of species diversity. - Proc. Natl Acad. Sci. USA 108: 5638-5642.

Allesina, S. and Tang, S. 2012. Stability criteria for complex ecosystems. - Nature 483: 205-208.

Alonso, D. et al. 2006. The merits of neutral theory. - Trends Ecol. Evol. 21: 451-457.

Baasch, A. et al. 2009. Insights into succession processes using temporally repeated habitat models: results from a long-term study in a post-mining landscape. - J. Veg. Sci. 20: 629-638.

Bennett, J. A. et al. 2013. Increased competition does not lead to increased phylogenetic overdispersion in a native grassland. - Ecol. Lett. 16: 1168-1176.

Bochet, E. et al. 2007. Road slope revegetation in semiarid Mediterranean environments. Part I: seed dispersal and spontaneous colonization. - Restor. Ecol. 15: 88-96.

Borthagary, A. I. et al. 2014. Inferring species roles in metacommunity structure from species co-occurrence networks. - Proc. R. Soc. B: 281: 2014.1425. 
Bowker, M. A. et al. 2010. Competition increases with abiotic stress and regulates the diversity of biological soil crusts. - J. Ecol. 98: 551-560.

Butaye, J. et al. 2001. Differential colonization causing nonrandom forest plant community structure in a fragmented agricultural landscape. - Ecography 24: 369-380.

Callaway, R. M. and Walker, L. R. 1997. Competition and facilitation: a synthetic approach to interactions in plant communities. - Ecology 78: 1958-1965.

Chamberlain, S. A. et al. 2014. How context dependent are species interactions? - Ecol. Lett. 17: 881-890.

Chesson, P. 2000. Mechanisms of maintenance of species diversity. - Annu. Rev. Ecol. Syst. 31: 343-366.

Connell, J. H. and Slatyer, R. O. 1977. Mechanisms of succession in natural communities and their role in community stability and organization. - Am. Nat. 111: 1119-1144.

Cuddington, K. and Hastings, A. 2004. Invasive engineers. - Ecol. Modell. 178: 335-347.

del Moral, R. 2009. Increasing deterministic control of primary succession on Mount St. Helens, Washington. - J. Veg. Sci. 20: 1145-1154.

Diamond, J. M. 1975. Assembly of species communities. - In: Cody, M. L. and Diamond, J. M. (eds), Ecology and evolution of communities. Harvard Univ. Press, pp. 342-444.

Djurdjević, L. et al. 2011. An allelopathic investigation of the domination of the introduced invasive Conyza canadensis L. - Flora 206: 921-927.

Dullinger, S. et al. 2007. Weak and variable relationships between environmental severity and small-scale co-occurrence in alpine plant communities. - J. Ecol. 95: 1284-1295.

Dzwonko, Z. 1993. Relations between the floristic composition of isolated young woods and their proximity to ancient woodland. - J. Veg. Sci. 4: 693-698.

Elton, C. S. 1958. The ecology of invasions by animals and plants. - Univ. of Chicago Press.

Gerwin, W. et al. 2009. The artificial catchment "Chicken Creek" (Lusatia, Germany) - a landscape laboratory for interdisciplinary studies of initial ecosystem development. - Ecol. Engin. 35: 1786-1796.

Gilpin, M. E. 1975. Limit cycles in competition communities. - Am. Nat. 109: 51-60.

Gioria, M. and Osborne, B. A. 2014. Resource competition in plant invasions: emerging patterns and research needs. - Front. Plant Sci. 5: e501.

Götzenberger, L. et al. 2011. Ecological assembly rules of plant communities - approaches, patterns and prospects. - Biol. Rev. 87: 111-127.

Gotelli, N. J. and Ulrich, W. 2012. Statistical challenges in null model analysis. - Oikos 121: 171-180.

Grime, J. P. 1973. Competitive exclusion in herbaceous vegetation. - Nature 242: 344-347.

Grime, J. P. 2001. Plant strategies, vegetation processes and ecosystem properties. - Wiley.

Harper, J. L. 1977. Population biology of plants. - Blackburn Press.

Hawkins, B. A. 2012. Eight (and a half) deadly sins of spatial analysis. - J. Biogeogr. 39: 1-9.

Horn, H. S. 1974. The ecology of secondary succession. - Annu. Rev. Ecol. Syst. 5: 25-37.

Horner-Devine, M. C. et al. 2007. A comparison of taxon cooccurrence patterns for macro- and microorganisms. - Ecology 88: 1345-1353.

Hubbell, S. P. 2001. The unified theory of biogeography and biodiversity. - Princeton Univ. Press.

Huisman, J. et al. 2001. Towards a solution of the plankton paradox: the importance of physiology and life history. - Ecol. Lett. 4: 408-411.

Keddy, P. A. 1992. Assembly and response rules - two goals for predictive community ecology. - J. Veg. Sci. 3: 157-164.
Kerr, B. et al. 2002. Local dispersal promotes biodiversity in a reallife game of rock-paper-scissors. - Nature 418: 171-174.

Kikvidze, Z. et al. 2005. Linking patterns and processes in alpine plant communities: a global study. - Ecology 86: 1395-1400.

Laird, R. A. and Schamp, B. S. 2006. Competitive intransitivity promotes species co-existence. - Am. Nat. 168: 182-193.

Latzel, V. et al. 2011. The association of dispersal and persistence traits of plants with different stages of succession in central European man-made habitats. - Folia Geobot. 46: 289-302.

Leibold, M. A. and Mikkelson, G. M. 2002 Coherence, species turnover, and boundary clumping: elements of meta-community structure. - Oikos 97: 237-250.

Lloyd, M. 1967. 'Mean crowding'. - J. Anim. Ecol. 36: 1-30.

Londo, G. 1976. The decimal scale for releves of permanent quadrats. - Vegetatio 33: 61-64.

Maestre, F. T. et al. 2009. On the relationship between abiotic stress and co-occurrence patterns: an assessment at the community level using soil lichen communities and multiple stress gradients. - Oikos 118: 1015-1022.

Maire, V. et al. 2012. Habitat filtering and niche differentiation jointly explain species relative abundance within grassland communities along fertility and disturbance gradients. - New Phytol. 196: 497-509.

Mata, T. M. et al. 2013. How invader traits interact with resident communities and resource availability to determine invasion success. - Oikos 122: 149-160.

Meiners, S. J. et al. 2015. Is successional research nearing its climax? New approaches for understanding dynamic communities. - Funct. Ecol. 29: 154-164

Meynard, C. N. et al. 2013. Disentangling the drivers of metacommunity structure across spatial scales. - J. Biogeogr. 40: 1560-1571.

Newman, M. E. J. 2006. Modularity and community structure in networks. - Proc. Natl Acad. Sci. USA 103: 8577-8582.

Olesen, J. M. et al. 2007. The modularity of pollination networks. - Proc. Natl Acad. Sci. USA 104: 19891-19896.

Palmer, M. A. et al. 1997. Ecological theory and community restoration ecology. - Restor. Ecol. 5: 291-300.

Patterson, B. D. and Atmar, W. 1986. Nested subsets and the structure of insular mammalian faunas and archipelagos. - Biol. J. Linn. Soc. 28: 65-82.

Perry, G. et al. 2003. Founder control and coexistence in a simple model of asymmentric competition for light. - J. Theor. Ecol. 222: 425-436.

Pickett, S. T. A. et al. 1987. A hierarchical consideration of causes and mechanisms of succession. - Vegetatio 69: 109-114.

Presley, S. J. et al. 2010. A comprehensive framework for the evaluation of metacommunity structure. - Oikos 119: 908-917.

Reichenbach, T. et al. 2007. Mobility promotes and jeopardizes biodiversity in rock-paper-scissors games. - Nature 448: 1046-1049.

Rojas-Echenique, J. R. and Allesina, S. 2011. Interaction rules affect species coexistence in intransitive networks. - Ecology 92: 1174-1180.

Soliveres, S. et al. 2011. Microhabitat amelioration and reduced competition among understorey plants as drivers of facilitation across environmental gradients: towards a unifying framework. - Persp. Plant Ecol. Evol. Syst. 13: 247-258.

Soliveres, S. et al. 2015. Intransitive competition is widespread in plant communities and maintains their species richness. - Ecol. Lett. 18: 790-798.

Tuomisto, H. et al. 2014. Species richness and diversity along edaphic and climatic gradients in Amazonia. - Ecography 37: 1034-1046.

Ulrich, W. and Gotelli, N. J. 2010. Null model analysis of species associations using abundance data. - Ecology 91: 3384-3397.

Ulrich, W and Gotelli, N. J. 2013. Pattern detection in null model analysis. - Oikos: 122: 2-18. 
Ulrich, W. et al. 2009. A consumer's guide to nestedness analysis. - Oikos 118: 3-17.

Ulrich, W. et al. 2014a. Variability in climate and soil attributes control plant species turnover in global drylands. - J. Biogeogr.: 41: 2307-2319.

Ulrich, W. et al. 2014b. Matrix models for quantifying competitive intransitivity from species abundance data. - Oikos 123: 1057-1070.

Ulrich, W. et al. 2014c. Small-scale spatial variability in phylogenetic community structure during early plant succession depends on soil properties. - Oecologia 175: 985-995.

Ulrich, W. et al. 2014d. Soil conditions and phylogenetic relatedness influence total community trait space during early plant succession. - J. Plant. Ecol. 7: 321-329.

Supplementary material (available online as Appendix oik-02658 at <www.oikosjournal.org/appendix/oik-02658>). Appendix 1.
Webb, C. O. et al. 2002. Phylogenies and community ecology. - Annu. Rev. Ecol. Syst. 33: 475-505.

Weiher, E. and Keddy. P. (eds) 1999. Ecological assembly rules: perspectives, advances, retreats. - Cambridge Univ. Press.

Zaplata, M. K. et al. 2010. Vegetation development. - In: Schaaf, W. et al. (eds), Initial development of the artificial catchment 'Chicken Creek'- monitoring program and survey 2005-2008. - Ecosyst. Develop. 2: 71-96.

Zaplata, M. K. et al. 2013. Increasing structure and species-driven phases in plant communities during early succession. - Am. Nat. 181: E17-E27.

Zuquim, G. et al. 2014. Predicting environmental gradients with fern species composition in Brazilian Amazonia. - J. Veg. Sci. 25: 1195-1207. 